1 Cooperative Research Centre for Water Sensitive Cities, Monash University, Australia

2 School of Earth Atmosphere and Environment, Monash University, Australia

3 Infectious Diseases and Geographic Medicine, Stanford University, USA

Correspondence to: THF Wong Tony.Wong@monash.edu

Cite this as: BMJ 2020;371:m4313 http://dx.doi.org/10.1136/bmj.m4313 Published: 16 November 2020
HEALTHY DRY CITIES

\section{Planetary health approaches for dry cities: water quality and heat mitigation}

\section{Water sensitive cities show how holistic approaches can counter the health and wellbeing problems associated with urban dryness, write Tony Wong, Nigel Tapper, and Stephen Luby}

Tony H F Wong, ${ }^{1}$ Nigel J Tapper, ${ }^{2}$ Stephen P Luby ${ }^{3}$

About 1.6 billion people live in countries with water scarcity, and this number is projected to double in two decades. ${ }^{1}$ Cities tend to conflate and amplify the challenges this brings, adversely affecting the health and wellbeing of their inhabitants.

Global increases in population and urbanization have increased demand for natural resources such as water. Climate change has exacerbated the effect of these trends, and many cities now have insufficient water supply to meet demand. ${ }^{2}$ Long term adaptation of global cities to climate change is crucial, especially as it can also improve the urban environment, provide health benefits, and mitigate further climate change.

Many responses to 21st century water challenges continue to rely on entrenched technocratic approaches of the 2oth century such as trunk supply of potable water for all purposes. Contemporary approaches to improving population health, however, emphasize holistic responses with social as well as physical dimensions, as Frumkin and colleagues highlight.

New or adapted water infrastructure should be integrated, flexible, and adaptive, incorporating "nature based solutions." Simultaneously, social resilience should be strengthened to improve health outcomes, including through raising community awareness of water insecurity and the behavioral changes needed and building societal capacity for innovation. Governments need to create the environment in which such transformations can occur.

Contemporary urban water management affects population health in two ways. Firstly, water scarcity can reduce the quality of water accessed by urban populations, worsening health and wellbeing, particularly among poorer and more vulnerable populations. Secondly, increasing frequency and intensity of heat waves affect population morbidity and mortality. We use our experience of managing water in informal settlements in developing countries to show the challenges that these communities face, with possible solutions that approach water scarcity holistically.

\section{Integrated urban water management and water sensitive cities}

Over the past decade, city planners, water authorities, practitioners, and researchers in Australia have collaborated to envision "water sensitive cities," and their principles are now emerging in city design. ${ }^{4}$
This new model has emerged in scientific, policy, and practice domains and is embodied in concepts such as integrated water cycle management. ${ }^{5}$ This is a vision of holistic urban water management incorporating physical and social dimensions, including water availability for potable and non-potable uses such as industry and agriculture; safety from flooding; safety from waterborne diseases and urban heat; health and wellbeing associated with biodiversity and ecological health; and social cohesion associated with green public spaces.

Integrated water cycle management aligns with planetary health framing. ${ }^{6}$ Although the challenges of water security are acute in dry cities, the water sensitive cities approach is relevant in all climates.

Two key principles of water sensitive cities are that our cities are water supply catchments and that they provide ecosystem services. In essence, water sensitive cities efficiently use the diverse water resources available within their boundaries, including recycled water and stormwater; enhance and protect the health of urban waterways and wetlands; and mitigate flood risk and damage.

Water sensitive cities create public spaces and green infrastructure that harvest, clean, and recycle water, increase biodiversity, sequester carbon, and reduce urban heat island effects (whereby cities tend to be hotter than surrounding rural areas). A third principle espouses building and nurturing the social capital within cities for climate adaptation and resilience. governance arrangements and can improve the health and wellbeing of communities vulnerable to diminishing water security.

\section{Protecting water quality}

Water scarcity affects access to water of sufficient quality, as well as quantity. Sources used for drinking, washing, and recreation that are contaminated with fecal waste expose the community to serious health risks; fecal-oral transmitted diseases are a leading cause of death for children globally. These challenges are not confined to dry settings. Many cities in wetter climates are still challenged by seasonality and variability of water availability, water quality, and equitable access to suitable water sources.

A common response to increasing demand and diminishing capacity is to supply water for only a few hours a day. But intermittent supply can These social-technical concepts reframe our water 
recontaminate treated water with fecal organisms as contaminated water can intrude through joints and cracks in the water network as it is intermittently depressurised, further worsening health outcomes. ${ }^{78}$ The pathways are often associated with groundwater contamination caused by poor sanitation and drainage services, contamination from floods, and anthropogenic pollution of waterways.

Contaminated water sources (including groundwater) and living environments profoundly affect the health and wellbeing of people living in slums or informal settlements. These people are among the most disadvantaged urban dwellers, lacking conventional trunk infrastructure approaches of the 2oth century, and bearing the brunt of increasingly severe droughts and floods. $9^{10}$ They show the intrinsic link between ecological and population health. No access to clean water and sanitation, combined with poor drainage and a lack of flood management, exposes residents to multiple fecal contamination pathways. Frequent floods expose residents to a high level of environmental fecal contamination, with their vulnerability exacerbated by extreme events arising from climate change.

Framed by planetary health principles, a water sensitive cities approach developed alternatives to current sanitation solutions for informal settlements. A randomized controlled trial in Indonesia and Fiji is evaluating these interventions for improvements to population health and wellbeing, and also ecological health. ${ }^{11}$ This research may offer an alternative to failed 2oth century approaches by deploying nature based solutions that respond to social and physical context.

The interventions, formulated through a community co-design process, combine established approaches to water, sanitation, and drainage services with nature based technologies that fit into dense urban communities. This effort combines expertise from many disciplines, including epidemiology, water engineering, ecology, landscape architecture, urban water governance, and behavioral science. The interventions concurrently aim to tackle water scarcity, non-existent or inadequate sanitation services, flooding and associated contamination, and a degraded water environment from poor land use and industry practices. Specifically, they include access to a variety of sources of water with quality that is fit for purpose, safe collection and treatment of sewage and grey water, improved flood protection and drainage, and the use of nature based systems to improve the ecological health and quality of the natural and built environment. Underpinning the success of all of these interventions is the change in attitude, behavior and day-to-day practices of residents. Figure 1 shows the development of a water sensitive intervention in a typical slum environment, providing flood-free access to dwellings with local sewage collection and treatment through a constructed wetland built along the accessway.
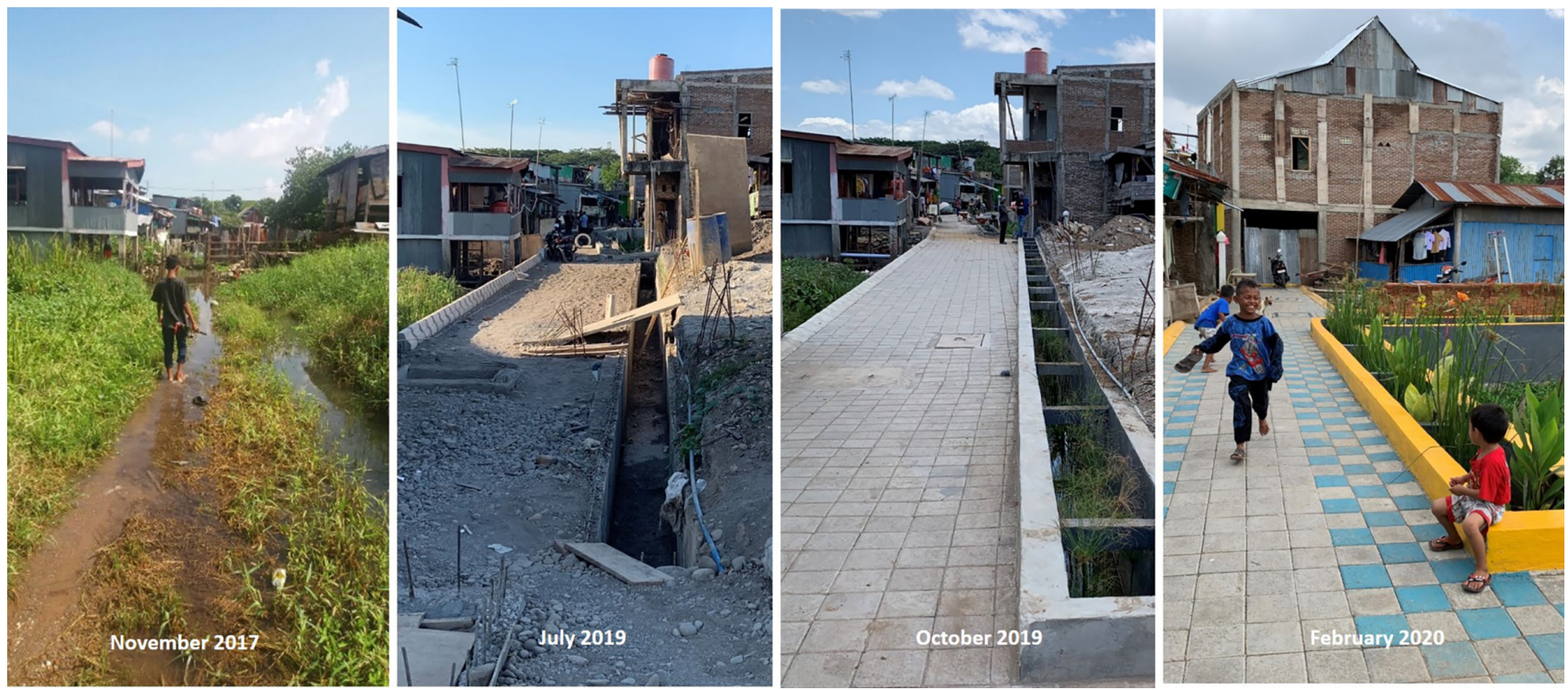

Fig 1 | Water sensitive slum upgrading interventions providing flood-free and contamination-free access to dwellings with a sewage network and wetland technology for safe sanitation services at Batua, Makassar, Indonesia

Co-designing the interventions with communities is essential for capturing specific biophysical context of fecal contamination pathways such as sanitation practices, flood vulnerability, drainage efficacy, and locations of daily activities, including children's play, domestic solid waste disposal, and household cooking and washing. The process also raises communities' awareness of their environment and vulnerability to fecal contamination and thus strengthens community resilience to improve hygiene practices. The participatory co-design promotes community understanding of the functional roles and benefits of hybrid nature based interventions and willingness to take responsibility for operating and maintaining the interventions. These include periodic maintenance of mechanical parts, desludging of the communal septic tank, maintaining healthy wetland plants, and routine surveillance of the operational efficacy of the interventions.

\section{Reducing mortality and morbidity from urban heat}

Increasing heat wave conditions expose cities and towns to another public health concern. Extreme heat events in Australia, for example, have caused more deaths since 1900 than any other natural hazard. An examination of extreme heat events in Australia from 1844 to 2010 found the number of deaths attributed to heat exposure was 4555 ( $55 \%$ of total deaths caused by natural hazard) compared with 1221 from flooding, the next highest cause of death. Causes of death were assessed from several sources including the media, government reports, and death certificates, and the estimated 
number of deaths attributed to heat exposure is a lower bound estimate. $^{12}$

Post-event analysis shows clear temperature thresholds or tipping points across all climate zones of Australia, with little adverse health response below thresholds but substantial rises in adverse health outcomes above them. A study in Melbourne (which has a dry hot summer climate) identified an average 24 hour temperature threshold of $28-30^{\circ} \mathrm{C},{ }^{13}$ above which mortality increased by $15-17 \%$ for people older than 65 (fig 2).

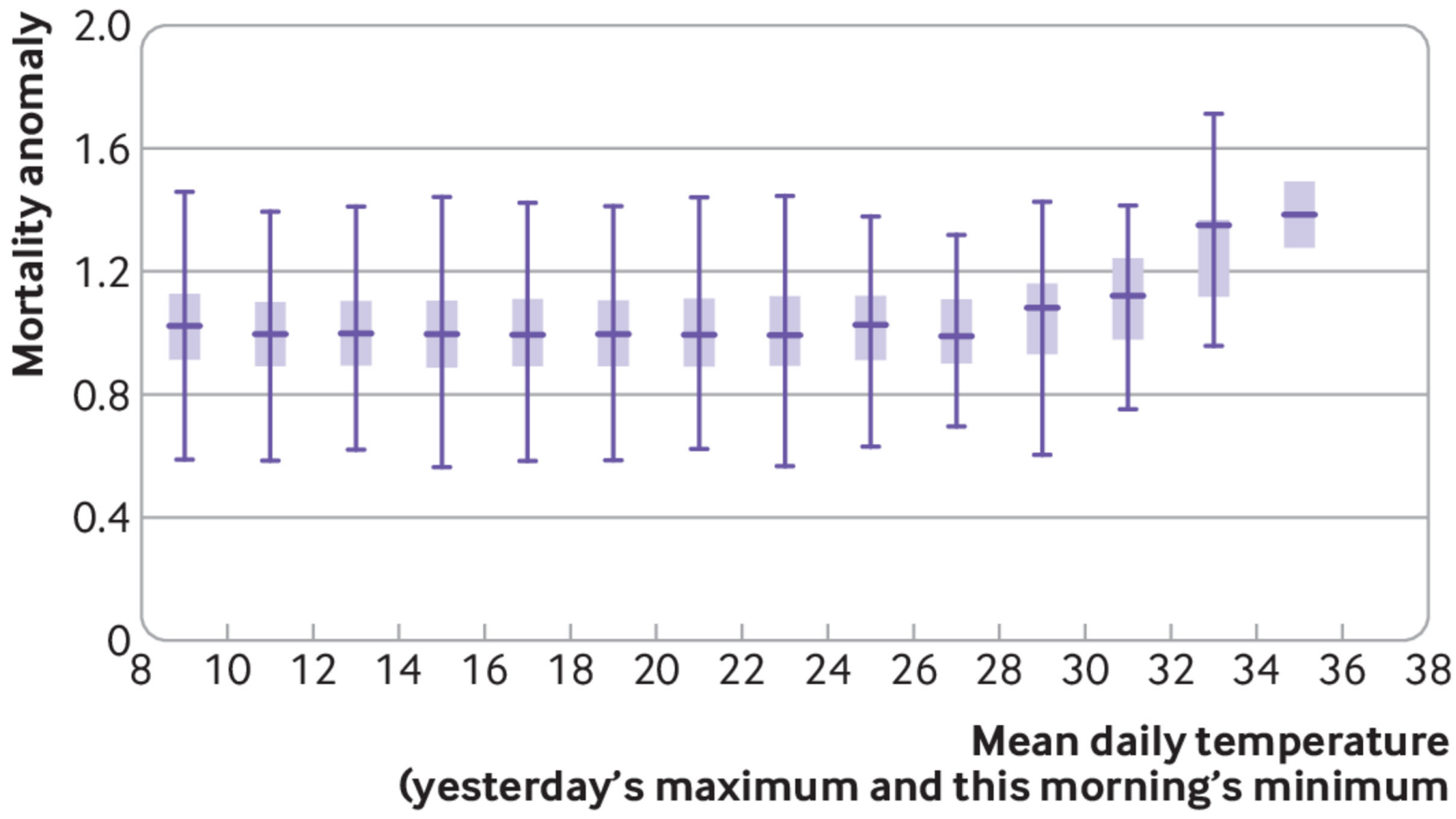

Fig 2 | Mortality anomalies (excess deaths) associated with heat among $>65$ year olds for Melbourne, Australia. Mortality rises substantially for temperatures above $28-30^{\circ} \mathrm{C}^{13}$

A subsequent study developed a heat vulnerability index ${ }^{14}$ that extended the heat threshold concept to all Australian capital cities, including those with wetter and humid sub-tropical and tropical climates. This work showed clear spatial patterns of vulnerability relating to socioeconomic factors and led to better preparedness among the population and emergency services along with targeted cooling interventions that have saved lives. ${ }^{15}$

Strategies to reduce temperatures by $1-2^{\circ} \mathrm{C}$ at the critical heat thresholds will reduce heat related mortality and morbidity. For example, installing fountains and misting systems increases direct evaporative cooling; creating lakes and ponds provides surfaces that stay relatively cool in daytime. Urban greening such as forests, parks, vertical gardens, and other nature based features contribute to cooling through evapotranspiration and shading (fig 3). But all these strategies increase water demand. The principle that cities are water supply catchments indicates that recycled water and stormwater could be used. 


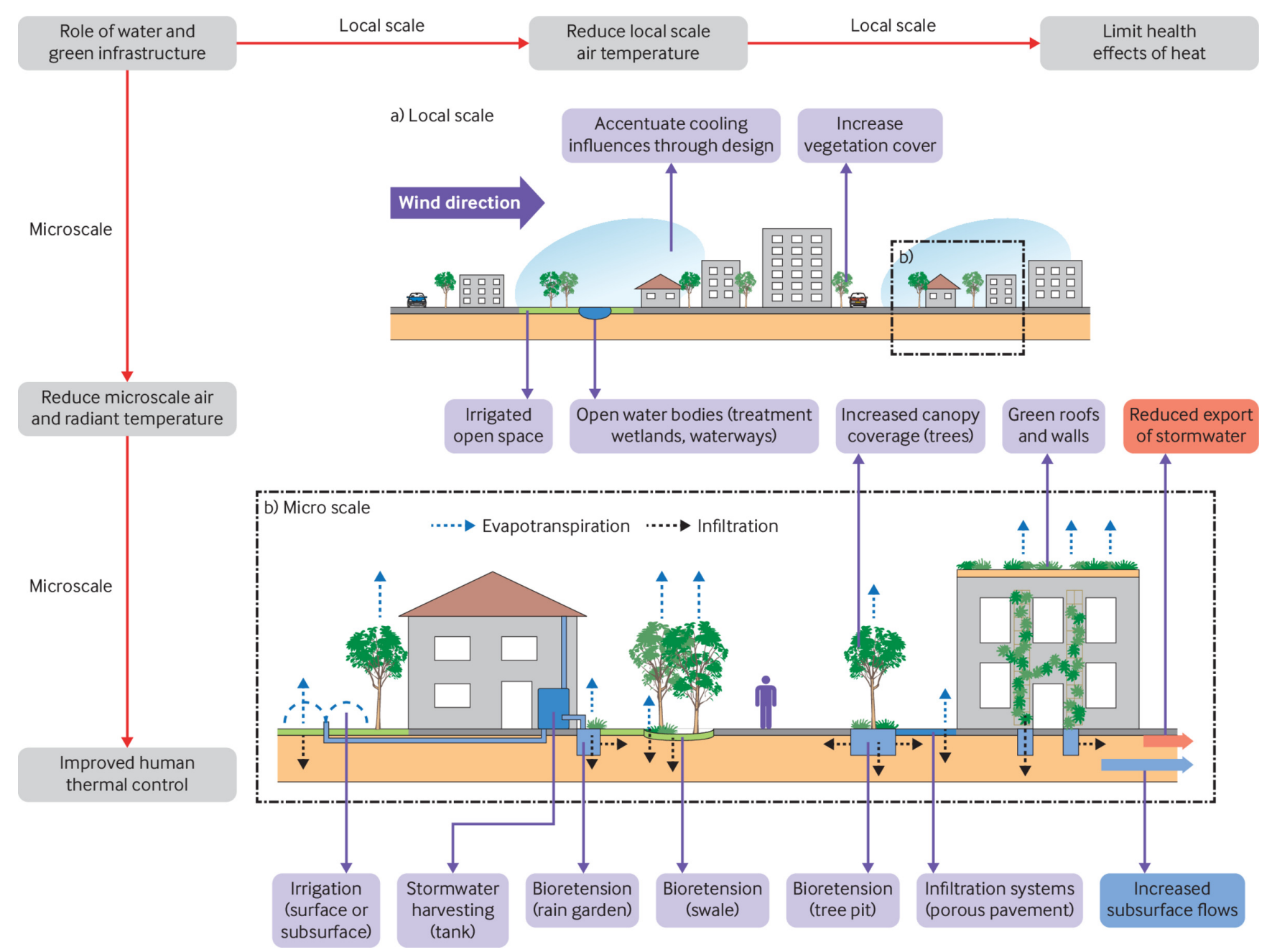

Fig 3 | Water sensitive city cooling technologies ${ }^{15}$

\section{Intrinsic link between ecological and population health}

The potential health benefits of a water sensitive approach are not confined to dry cities. Evidence based policy drawing on the many dimensions of urban design and water management could improve the health and wellbeing of all communities. Water sensitive city approaches highlight the intrinsic link between ecological and population health, and how urban water management can benefit both aspects. They also highlight the importance of supporting physical interventions by building or strengthening social resilience, through greater community awareness and society's capacity for fostering transformative change.

\section{Biography}

Tony Wong is formerly chief executive of the Cooperative Research Centre for Water Sensitive Cities and now chairs its think tank. He is a pioneer in the water sensitive cities approach and has enabled creative urban design through blending biomimicry with engineering and architectural knowledge and practices for delivering sustainable urban water outcomes. Nigel Tapper is an IPCC lead author, serves in the UN World Meteorological Organisation as a climate change adaptation expert, and is president of the International Association of Urban Climate. He holds a personal chair in environmental science at Monash University, Australia, where his recent work has been in developing innovative approaches to cool cities under extreme heat conditions.
Stephen Luby is director for research at Stanford's Center for Innovation in Global Health. He has worked full time on health research in low income countries for the past 25 years, including living in Pakistan for five years and Bangladesh for eight years. He is particularly interested in developing and evaluating approaches to counter the perverse incentives where people earn money by destroying the environment and health.

Competing interests: We have read and understood BMJ policy on declaration of interests and have no interests to declare.

Provenance and peer review: Commissioned; externally peer reviewed.

This article is part of a series commissioned by The BMJ for the World Innovation Summit for Health (WISH) 2020. The BMJ peer reviewed, edited, and made the decisions to publish. The series, including open access fees, is funded by WISH.

1 World Bank. High and dry: climate change, water, and the economy. 2016. https://documents.worldbank.org/en/publication/documents-reports/documentdetail/862571468196731247/high-anddry-climate-change-water-and-the-economy

2 Rockström J, Steffen W, Noone K, etal. A safe operating space for humanity. Nature 2009;461:472-5. doi: 10.1038/461472a pmid: 19779433

3 Frumkin H, Das MB, Negev M, etal. Protecting health in dry cities: considerations for policy makers. BMJ 2020;371:m2936. doi: 10.1136/bmj.m2936 pmid: 33127838

4 Wong THF, Rogers B, Brown RR. Transforming cities through water sensitive principles and practices. One Earth 2020;3:436-47. doi: 10.1016/j.oneear.2020.09.012.

5 Wong THF. Human settlements - a framing paper for the high-level panel on water. Australian Water Partnership, 2016. https://waterpartnership.org.au/wp-content/uploads/2016/08/HLPWHuman-Settlements.pdf 
6 Horton R, Lo S. Planetary health: a new science for exceptional action. Lancet 2015;386:1921-2. doi: 10.1016/S0140-6736(15)61038-8 pmid: 26188746

7 Kumpel E, Nelson KL. Comparing microbial water quality in an intermittent and continuous piped water supply. Water Res 2013;47:5176-88. doi: 10.1016/j.watres.2013.05.058 pmid: 23866140

8 Ercumen A, Gruber JS, Colford JMJr. Water distribution system deficiencies and gastrointestinal illness: a systematic review and meta-analysis. Environ Health Perspect 2014;122:651-60. doi: 10.1289/ehp.1306912 pmid: 24659576

9 CRC for Water Sensitive Cities. Strengthening the delivery of WASH in urban informal settlements: addressing multiple exposure pathways in urban environments. Cooperative Research Centre for Water Sensitive Cities, 2018.

10 Luby SP, Davis J, Brown RR, Gorelick SM, Wong THF. Broad approaches to cholera control in Asia: Water, sanitation and handwashing. Vaccine 2020;38(Suppl 1):A110-7. doi: 10.1016/..vaccine.2019.07.084 pmid: 31383486

11 Brown RR, Leder $\mathrm{KS}$, Wong T, etal. Improving human and environmental health in urban informal settlements: the revitalising informal settlements and their environments (RISE) programme. Lancet Planet Health 2018;2:S29. doi: 10.1016/S2542-5196(18)30114-1

12 Coates L, Haynes K, O'Brien J, McAneney J, de Oliveira F. Exploring 167 years of vulnerability: An examination of extreme heat events in Australia 1844-2010. Environ Sci Policy 2014:42:33-44doi: 10.1016/j.envsci.2014.05.003

13 Nicholls N, Skinner C, Loughnan M, Tapper N. A simple heat alert system for Melbourne, Australia Int J Biometeorol 2008;52:375-84. doi: 10.1007/s00484-007-0132-5 pmid: 18058138

14 Loughnan M, Tapper N, Phan T, Lynch K, Mclnnes J. A spatial vulnerability analysis of urban populations during extreme heat events in Australian capital cities. National Climate Change Adaptation Research Facility, 2013.

15 Tapper N. Creating cooler, healthier and more liveable Australian cities using irrigated green infrastructure. In: Ren C, McGregor G, eds. Urban climate science for planning healthy cities. Springer (forthcoming).

This is an Open Access article distributed in accordance with the Creative Commons Attribution Non Commercial (CC BY-NC 4.0) license, which permits others to distribute, remix, adapt, build upon this work non-commercially, and license their derivative works on different terms, provided the original work is properly cited and the use is non-commercial. See: http://creativecommons.org/licenses/by$\mathrm{nc} / 4.0 \%$ 